\title{
Formação do éthos diverso e Educação das relações étnico-raciais
}

\author{
Amauri Carlos Ferreira* \\ Lorene dos Santos ${ }^{* *}$
}

\begin{abstract}
Resumo
A morada da ética é o outro. Mas quem é este outro? De que outro falamos no ambiente escolar? É possível educar para a diversidade? A partir destas indagações procuramos discutir a questão do outro que indagou a ética e a educação no início dos anos de 1990. Este artigo está circunscrito na fronteira da relação professor/estudante, tendo como elemento interveniente o preconceito com os recém-chegados à escola. Para melhor compreender a formação do éthos diverso em abordagens contra o preconceito, tecemos reflexões no campo da diversidade étnico racial. Foram mapeadas algumas conquistas no plano da legislação e das políticas públicas em educação. Apresentamos dados de pesquisas que evidenciam formas de manifestação do preconceito racial e alguns dos dilemas e desafios de professores comprometidos com o trato da diversidade na construção de novas relações no espaço escolar.

Palavras Chaves: Educação; Ética; Diversidade; Preconceito racial;
\end{abstract}

\section{Building the éthos of diversity and education of ethnic racial relationships}

\begin{abstract}
The living place of ethics is the Other. But, who is the Other? Who is this Other we talk about in the academic environment? Is it possible to educate for diversity? These questions are the starting point of a discussion about the Other that questioned ethics and education in the 1990's. This paper is about the teacher/student relationship, focusing on discrimination against the newcomers in school. A better understanding of the process of building the éthos of diversity comes from reflections in the field of racial ethnic diversity. We maped the achievements against discrimination in the legislative domain and public policy education. Our research data indicates various manifestations of racial prejudice and some of the dilemmas and challenges teachers committed to diversity when dealing with new relationships in school.

Keywords: Education; Ethics; Diversity; Racial prejudice.
\end{abstract}

\section{Introdução}

A morada da diversidade é ética e política (FERREIRA, 2011, p.69).

É no encontro com o outro que a ética oferece possibilidades para se refletir sobre valores de uma determinada época, ou do próprio agir do indivíduo no mundo. Tal perspectiva permite entender que o campo da ética faz parte da filosofia prática que ocupa, no território da ação, seu lugar privilegiado. Este agir do indivíduo constrói e reconstrói o éthos ao longo da vida. É assim que a relação com o outro demanda uma perspectiva ética ao tocar a sensibilidade na relação eu/outro, exigindo respeito ao direito de existir no mundo.

O outro com o qual lidamos no espaço escolar da educação básica é a criança e o adolescente, que exigem um tempo de dedicação das instituições de formação, tais como a religião, a família e a escola. Na educação básica, cuidamos da formação deste outro numa perspectiva da ética do cuidado. A palavra "cuidado" está ancorada sobre *PUC MINAS - Endereço eletrônico: mitolog@ pucminas.br **PUC MINAS - Endereço eletrônico: lorenedossantos@gmail.com duas áreas do conhecimento humano: saúde e educação. A primeira cuida do corpo e a segunda, do espírito. Na primeira, a palavra latina "coera" remete ao que vai proporcionar cura. $\mathrm{O}$ adulto que detém um conhecimento sobre determinada área do saber se curva ao outro, que está frágil, e tenta curá-lo. Na segunda, o adulto que sabe mais, em termos de vivência, diante daquele que está chegando ao mundo, curva-se a ele e o conduz ao que considera ser o correto para sua vida. Nesta ideia de condução, o educador de crianças e adolescentes conduz os recém-chegados ao mundo a partir da construção de valores da época em que se vive.

A partir dos anos 90 do século passado, o outro que chegou à escola pública brasileira indagou nosso modo de compreendê-lo. De tal maneira, que a educação teve como dever refletir sobre este outro com seus direitos novos e a ética teve que refletir sobre este outro em sua concretude e singularidade.

Nesta direção, pensar um outro é repensar o próprio rosto, o que remete a Emmanuel Lévinas, quando afirma: 
Quando se vê o nariz, os olhos, a testa, um queixo e se podem descrever, é que nos voltamos para outrem como para um objeto. A melhor maneira de encontrar outrem é nem sequer atentar na cor dos olhos. Quando se observa a cor dos olhos, não se está em relação social com outrem... A relação com o rosto pode, sem dúvida, ser dominada pela percepção, mas o que é especificamente rosto é o que não se reduz a ele. $O$ rosto está exposto, ameaçado, como nos convidasse a um ato de violência. Ao mesmo tempo, o rosto é o que nos proíbe de matar (LEVINAS, 1982, p. 77-78).

O que chamamos de "um outro", em sua diversidade e diferença,foi sendo compreendido de diversas maneiras. Neste artigo, optamos por discutir a diversidade do ponto de vista étnico racial, no sentido de compreender o modo como temos sido indagados, tanto no campo educacional como ético. Assim, destacamos, no campo da formação do diverso e os desafios éticos da relação com os recém-chegados na escola, o enfrentamento do preconceito. Uma nova morada se fez necessária para compreender a morada da diversidade e trabalhar na perspectiva de educação das relações étnico raciais.

\section{A Nova Morada Ética: Diversidade e combate ao Preconceito}

O conceito de ética, ao longo do tempo, assume a construção e reconstrução do êthos como morada, lugar de ser no mundo, tendo como tema central os costumes de uma determinada cultura, de uma determinada época. Pode-se pensar a construção da ética em três momentos: a tradição grega, a tradição iluminista e a contemporânea. Para Ferreira (2010), a tradição grega, ao situar o homem na pólis, exige que o mesmo busque o ideal de justiça. Dessa forma, o caminho que leva à ciência do éthos, na Grécia, circunscreve-se aos séculos IV e V, mesmo compreendendo-se que esse ideal de ser justo procede de uma tradição anterior que remonta a Homero, em sua virtude guerreira, na qual a virtude da coragem impõe-se como marca do herói. A tradição iluminista, especificamente em Kant, considera o dever e a lei moral como centrais no cumprimento da norma, independentemente de concepções metafísicas ou religiosas. Kant estabelece a razão como fundamento da ética, sendo a consciência e a liberdade elementos centrais no campo da moralidade. A tradição contemporânea, com raiz na filosofia moderna, considera que os termos ética e moral, em sua semântica paralela, designando fundamentalmente costumes, passam a deter matrizes diferentes para a construção do éthos.

Estes marcos históricos da ética nos conduziram a pensar a ética aplicada, que exige a separação dos termos ética e moral. Segundo Lima Vaz (1999, p.15), o termo moral refluiu progressivamente para o terreno da práxis individual, enquanto o termo ética teve seu campo de significação ampliado, passando a abranger todos os aspectos da práxis social. A moral foi se configurando em seu aspecto de grupo ou de momentos históricos demarcados, de tal maneira que, o que é moral em uma época ou para um determinado grupo pode não ser em outro momento ou para um grupo distinto. Já o termo ética passou a ser designado e compreendido na relação com o outro. Assim, o elemento interveniente do éthos, na perspectiva da ética, é o outro.

O mundo contemporâneo trouxe um outro modo de compreender os costumes, de tal forma que a reflexão ética se tornou necessária, dando lugar à ética aplicada. A expressão "ética aplicada" surgiu nos Estados Unidos, nos anos 60 do século passado. Nos anos 70, as questões de ordem ética sedimentaram-se em áreas do conhecimento que tangenciavam o campo interdisciplinar, como bioética, ética ambiental, ética profissional, ética e educação, dentre outras que caracterizam um ramo específico da ética geral. A ética aplicada não se atém a princípios da ética geral, mas tenta buscar princípios que compõem sua origem utilitária, voltada para a ação do indivíduo. Para Martinez \& Cortina (2005, p.154):

A estrutura da ética aplicada não é dedutiva, nem indutiva, mas desfruta da circularidade própria de uma hermenêutica crítica, já que é nos diferentes âmbitos da vida social que detectamos como base um princípio ético (o do reconhecimento de cada um, de cada pessoa, como interlocutor válido) que modula de forma diferente segundo o âmbito que nos encontramos.

No campo da educação, as discussões da ética aplicada migraram para cotidiano das instituições educativas, dentre elas a escola. O que se pode perceber foram tentativas de pensar o outro, criança e adolescente, numa perspectiva da ética do cuidado, pressupondo uma responsabilidade para 
com os recém-chegados. Esta ética não avançou muito no que se refere a discussões teóricas e práticas, ficando circunscrita na obrigação como dever dos educadores das séries iniciais, ou no mundo e na prática isolada de alguns docentes. Nos anos de 1990, em que a ética retornou nas sociedades ocidentais como uma referência ao outro, o caráter abstrato reflexivo da ética permaneceu e não foi diferente no que se refere ao cuidado com o outro. A novidade, no caso da realidade brasileira, foi a entrada e permanência de novos sujeitos no espaço escolar, como parte dos princípios de garantia de direitos de igualdade para todos. A educação como direito universal assumiu, no final dos anos 80 do século $\mathrm{XX}$, na constituição de 1988, lugar de destaque.

Esta conquista de novos direitos, no plano legal, se materializou em políticas voltadas à ampliação de acesso e permanência das camadas populares nas escolas públicas. Estas, no entanto, foram recebidas em meio à reatualização de preconceitos e dos mecanismos de exclusão e estigmatização, uma vez que tanto as instituições de formação quanto as escolas e seus educadores não estavam acostumados com a entrada maciça destes novos sujeitos. Tal situação, desde os anos de 1990, tem sido marcada por uma educação que necessita se pautar para uma diversidade na qual o éthos em permanente construção tem que se reordenar, tanto no campo da formação teórica quanto prática.

Ao pensarmos este outro em sua diversidade, remetemos ao conceito de diverso, constatando que o ser humano é diverso por natureza. Esta diversidade pode ser compreendida de maneiras diferentes no campo mais geral, ao estabelecer as diferenças de um grupo em relação ao outro, destacando as diferenças físicas, sexuais, de crenças etc.

A diversidade que discutimos, no campo filosófico e da ética aplicada, é aquela que aponta para construção de um novo éthos tendo em vista que:

O diverso, mesmo sem consciência de sua razão de ser, é evidenciado e classificado em grupos/coletivos que o representam. Daí que o diverso é um elemento perturbador dentro de uma ordem já estabelecida mais do que a diferença dentro da história do pensamento. A diversidade inclui a construção social, histórica e cultural das diferenças. Aponta o pertencimento dos sujeitos sociais e coletivos que buscam se fazer respeitar pelas diferenças que possuem (FERREIRA; GOMES, 2011, p. 73).

A partir dos anos 2000, o tema da diversidade no campo das políticas públicas passou a ser dimensionado no campo dos direitos humanos, comparecendo nas conferências nacionais de educação básica, em 2008, como também na CONAE (Conferência Nacional de Educação), de 2010. Antes disso, diversas configurações do diverso vinham se impondo no cenário nacional educativo, tais como educação do campo, indígena, quilombola, da mulher, LGBT, necessidades educacionais, entre outros, exigindo a validade dos direitos sociais que emergiam de organizações da sociedade.

Se analisarmos a CONAE, percebemos a diversidade como integrante do processo pedagógico. No entanto, esta diversidade, ao que tudo indica, configurou no éthos legal sua generalidade e não a especificidade que os movimentos sociais demandam. $\mathrm{O}$ reconhecimento no plano legal é fundamental para a construção de ações afirmativas, mas não o suficiente em termos do éthos ético, que necessita refletir sobre o outro para ultrapassar preconceitos e intolerâncias. É certo que alguns avanços aconteceram neste campo, nos últimos anos. Nesta relação entre direitos humanos e diversidade, Gomes (2013, p. 233) aponta três avanços:

O primeiro deles é a visibilidade construída historicamente pelos diferentes coletivos sociais e pelos movimentos sociais. Esses sujeitos qualificam o discurso e as práticas educacionais e trazem para a sociedade, o Estado, as políticas educacionais, a universidade e a educação básica a necessária articulação entre educação, direitos humanos e diversidade. $O$ segundo avanço é a indagação trazida por estes coletivos e pelos movimentos sociais sobre qual é a concepção de direitos humanos que norteia nossas práticas e políticas educacionais e sociais. [...] $O$ terceiro avanço é a paulatina compreensão do campo educacional sobre a forte presença dos movimentos sociais como o coletivo que traz para a sociedade, o Estado e suas políticas a luta pelos direitos sociais, humanos, políticos, econômicos, travada em 
prol do direito à diversidade e da diferença.

Tais avanços são fundamentais para se refletir no campo da ética, dimensionando o diverso em sua concretude, tendo em vista este outro que tem uma identidade étnico-racial, pertence a um gênero, tem suas preferências sexuais e religiosas. Um outro que em sua diversidade sofre na escola a ausência de reconhecimento e o dever do adulto para com ele. Mesmo com os avanços apontados por Nilma Lino Gomes, nestes últimos anos, ainda não foi possível superar questões relacionadas ao racismo e à intolerância para com os diferentes.

Consideramos pertinente a perspectiva de Norberto Bobbio sobre preconceito e racismo, quando entende por preconceito:

[...] uma opinião ou um conjunto de opiniões, às vezes até mesmo uma doutrina completa, que é acolhida acrítica $e$ passivamente pela tradição, pelo costume ou por uma autoridade de quem aceitamos as ordens sem discussão; acriticamente e passivamente, na medida em que a aceitamos sem verificá-la, por inércia, respeito ou temor, e a aceitamos com tanta força que resiste a qualquer refutação racional, vale dizer, a qualquer refutação feita com base em argumentos racionais. Por isso se diz corretamente que o preconceito pertence à esfera do não racional, ao conjunto das crenças que não nascem do raciocínio e escapam de qualquer refutação fundada num raciocínio (BOBBIO, 2002, p. 119).

E ainda quando compreende racismo como uma atitude ou comportamento que se dirige a um grupo:

A condição preliminar para que surja uma atitude ou um comportamento racista é a entrada em contato direto com o outro, ou melhor, com os outros. $O$ racismo se dirige não tanto para a pessoa singular, diante da qual se pode ter sentimentos de ódio, desprezo, ou aversão, quanto para o grupo, ou para o indivíduo pertencente a um grupo (BOBBIO, 2002, p. 119).

Devemos considerar que, em nosso país, o racismo assumiu uma conotação própria, muito peculiar, que Oracy Nogueira chamou, em 1954, de "preconceito de marca - uma classificação quase imediata - por oposição ao preconceito de origem, mais próprio ao contexto norte-americano, no qual quem descende de uma família negra (a menos de três gerações), e a despeito da aparência, é sempre negro" (SCHWARCZ, 1998, p. 226). Assim, enquanto o racismo norte-americano tem como referência o genótipo, nosso racismo é pautado por traços fenotípicos, em que "certos traços físicos como formato do rosto, tipo de cabelo e coloração de pele se transformam nas principais variáveis da discriminação" (SCHWARCZ, 1998, p. 226). Além do "preconceito de marca", podemos identificar, em nosso país, "o uso privado do racismo, a manipulação social da raça e das cores, uma mestiçagem avançada, mas, também, um claro processo de exclusão social" (SCHWARCZ, 2006, p. 44), caracterizando o que alguns autores passam a denominar de "racismo à brasileira".

Assim, ao discutirmos o preconceito e racismo na educação,tomamos como referência diversos estudos que confirmam, há muitas décadas, a existência da discriminação racial, no Brasil. Embora não formalizada no plano das leis, ela se manifesta cotidianamente em ações e práticas sociais que negam direitos e perpetuam exclusões. Dados estatísticos sobre o acesso à educação, lazer, saúde e condições de saneamento básico, sobre a expectativa de vida, índices de mortalidade infantil, distribuição de renda e de bens culturais produzidos pela sociedade, entre outros indicadores sociais, evidenciam que a população negra ocupa uma posição desfavorável, resultado da ausência de uma distribuição equitativa de bens materiais e simbólicos e da desigualdade na conquista de direitos ${ }^{1}$.

Denunciado pelos movimentos negros, em diferentes momentos do século XX, o combate ao racismo tornou-se importante mote dos movimentos sociais $^{2}$, sobretudo a partir de fins dos anos 1970 , em meio à luta pela democracia e pelo fim do regime militar. Tal contexto configurou-se como momento de rearticulação e instauração de uma nova agenda política de combate antirracista, que segundo Guimarães (2005, p. 228), passa a se organizar em três frentes:

(a) recuperação da auto-estima negra, por meio da modificação de valores estéticos, da reapropriação de valores culturais, da recuperação de seu papel na história nacional, $e$ do avivamento do orgulho racial e cultural; (b) combate à 
discriminação racial, por meio $d a$ universalização da garantia dos direitos $e$ das liberdades individuais, incluindo os negros, mestiços e pobres; (c) combate às desigualdades raciais, por meio de políticas públicas que estabeleçam, a curto e médio prazo, um maior equilíbrio de riqueza, prestígio social e poder entre brancos $e$ negros.

A partir dos anos 1980, ocorreu uma crescente institucionalização de algumas das instâncias reivindicatórias, resultando no surgimento, em âmbito federal, estadual e municipal, de secretarias especiais, delegacias para crimes de racismo, conselhos, fóruns e programas diversos de luta contra a discriminação racial.

A Constituição Federal, de 1988, ao transformar o racismo em crime "imprescritível" e "inafiançável”, representou importante conquista no plano legal, mas a ineficácia do combate às práticas racistas no plano jurídico tem confirmado a necessidade de se construir novas e diversificadas estratégias, compreendendo a educação como campo privilegiado para o combate ao preconceito racial e às manifestações de intolerância no plano cultural e religioso. A preocupação em combater preconceitos e discriminações se coaduna com a perspectiva de valorização da diversidade sociocultural e étnico-racial brasileira, que passou a se fazer presente em diferentes documentos oficiais e programas curriculares surgidos no bojo das reformas educacionais dos anos 1990, como é o caso da Lei de Diretrizes e Bases da Educação Nacional - LDBEN 9.394/9633 - e dos Parâmetros Curriculares Nacionais ${ }^{4}$. No início deste novo século, registramos o surgimento de leis e de um conjunto de normatizações, órgãos e políticas públicas no campo da educação direcionados ao enfrentamento das desigualdades raciais e à valorização da diversidade cultural, destacando-se as leis $10.639 / 03$ e $11.645 / 08$, e as Diretrizes Curriculares Nacionais para a Educação das Relações Étnico-raciais e para o Ensino de História e Cultura Afro-Brasileira e Africana (2004). Vale lembrar, ainda, que desde os anos 1990, Constituições Estaduais, Leis Orgânicas e leis ordinárias municipais passaram a tratar da inclusão de conteúdos curriculares relacionados ao "estudo da Raça Negra" e contra a discriminação ${ }^{5}$. Particularmente nos últimos anos, têm crescido, em âmbito estadual e municipal, os investimentos de secretarias de educação e cultura, visando à introdução das temáticas africana e afro-brasileiras nos currículos escolares. Ações variadas, que incluem programas de formação continuada de professores, oficinas e palestras direcionadas a pais, alunos e comunidade em geral, distribuição de kits de materiais didáticos e paradidáticos, entre outras iniciativas, têm favorecido novas abordagens da temática africana e afro-brasileira na educação básica. Mas o processo de recepção à nova legislação educacional é atravessado pela conjugação de inúmeros fatores, grande parte deles relacionados ao contexto específico de cada instituição escolar e de cada sala de aula, em particular. O momento atual demanda um olhar mais cuidadoso para o que está acontecendo efetivamente no interior das escolas e salas de aula, campo privilegiado para o encontro entre diferentes identidades - geracionais, étnico-raciais, de gênero, orientação sexual e culturais, em geral. Lugar de aprendizado da alteridade, mas também da perpetuação de intolerâncias e práticas discriminatórias, em situações cotidianas que convocam os educadores a refletirem sobre a dimensão ética do respeito ao outro e do acolhimento do diverso.

\section{A morada da diversidade étnico racial: quando o diverso interroga a escola}

Vera Candau, em uma obra que traz o instigante título "Somos todas iguais?" (2003), problematiza a permanência de práticas discriminatórias no ambiente escolar, em contraponto ao propósito de uma "educação em direitos humanos". A autora nos lembra que:

O cotidiano da escola é palco de diferentes relações sociais e reflete a diversidade cultural presente na sociedade. Assim, diferentes visões de mundo, estilos de vida, crenças, costumes, cores, etnia e todos os aspectos que compõem a cultura frequentam, diariamente, as salas de aula. A instituição escolar representa um microuniverso social, que se caracteriza pela diversidade social e cultural e por, muitas vezes, reproduzir padrões de conduta que permeiam as relações sociais fora da escola. Desse modo, as formas de se relacionar com o outro, na escola, refletem as práticas sociais mais amplas. Podemos dizer que, ainda que valores como igualdade e solidariedade, respeito ao 
próximo e às diferenças estejam presentes no discurso da escola, outros mecanismos, talvez mais sutis, revelam que preconceitos e estereótipos também integram o cotidiano escolar. Os veículos de discriminação vão desde o currículo formal, que exclui múltiplas e variadas maneiras de expressão cultural, passando pela linguagem nãoverbal, até chegarem, frequentemente, ao nível dos comportamentos e das práticas explícitas (CANDAU, 2003, p. 24).

As problematizações da autora podem ser confirmadas por inúmeras pesquisas que, nos últimos anos, vêm mapeando algumas das manifestações de discriminação racial no cotidiano escolar, ${ }^{6}$ reproduzidas tanto por estudantes, quanto por professores e outros agentes educativos. Apelidos pejorativos, recusa à convivência, olhares de desaprovação, baixa expectativa de aprendizagem são algumas das ações dirigidas privilegiadamente às crianças e adolescentes negras e negros. Às questões étnico-raciais somam-se outras dimensões da identidade que são alvo de preconceitos e discriminações. Problematizando os preconceitos de gênero, raça e classe social que adentram o cotidiano escolar, Candau (2003) ressalta que a situação se agrava ainda mais "no caso de crianças que conjugam duas ou mais dessas características, como as alunas negras e pobres, alvo de práticas discriminatórias que afetam seu autoconceito e sua auto-estima e induzem-nas a ver a si mesmas como inferiores às demais" (CANDAU, 2003, p. 25). Por manifestar-se de forma cotidiana e, muitas vezes, dissimuladamente, a discriminação acaba, em muitos casos, tornandose um evento banalizado e pouco combatido. Para as crianças e adolescentes vítimas de preconceito, nem sempre tais situações podem ser claramente compreendidas ou facilmente nomeadas, embora sejam duramente sentidas e tenham consequências perversas na construção de sua autoimagem e autoestima. Como poderá se sentir uma adolescente negra que, repetidamente, a cada ano, tem dificuldades para encontrar um par nas danças de quadrilha? O que fazer diante da criança negra que se fere ao passar palha de aço no próprio corpo, em uma atitude desesperada para "arrancar" a pele negra que a condena a tantas situações de exclusão e desqualificação? A autorresponsabilização pelo suposto fracasso ou a culpabilização por aspectos de sua aparência física, recorrentemente classificados como feios ou inadequados, tornam-se situações dramaticamente corriqueiras, levando ao isolamento e silenciamento das vítimas. A omissão dos educadores e demais adultos diante desses fatos acaba por reforçar uma naturalização dos eventos de racismo, sejam eles explícitos ou não, favorecendo a interiorização, por parte das crianças e adolescentes discriminados, de que o problema está com elas, e não com a sociedade que as discrimina. Quebrar esse círculo exige clareza, posicionamento, atitude e compromisso ético dos educadores. Compromisso com a criança e adolescente que é discriminado e também com aquele que discrimina, numa compreensão de que a reeducação das relações étnico-raciais não beneficia apenas os que são vítimas frequentes de preconceito e discriminação, mas é condição para a construção de uma ética do cuidado, cuidado com as novas gerações e responsabilidade com o mundo que as recebe. Como afirma contundentemente a filósofa Hanna Arendt, "Qualquer pessoa que se recuse a assumir a responsabilidade coletiva pelo mundo não deveria ter crianças, e é preciso proibi-la de tomar parte em sua educação. Na educação, essa responsabilidade pelo mundo assume a forma de autoridade" (ARENDT, 2000, p. 239). A responsabilidade coletiva pelo mundo, terreno da ética e da política, é assim uma condição do adulto educador. E essa responsabilidade com o mundo é também a responsabilidade pela transformação do mundo que aí está. Voltando a Arendt, em sua instigante provocação sobre como a educação deve ser essencialmente conservadora, no sentido de "abrigar e proteger alguma coisa - a criança contra o mundo, o mundo contra a criança, o novo contra o velho, o velho contra o novo" (p. 242), encontramos ainda o alerta de que essa atitude "conservadora" é válida apenas nas relações entre adultos e crianças. A autora postula, então, que a atitude conservadora na educação é exatamente uma condição para acolher a novidade que as novas gerações trazem ao mundo, sendo um compromisso político dos educadores contribuir para o rompimento com a atitude conservadora de preservação do status quo.

Tal atitude conservadora, em politica aceitando o mundo como ele é, procurando somente preservar o status quo -, não pode levar senão à destruição, visto que o mundo, tanto no todo como em parte, é irrevogavelmente fadado à ruína pelo tempo, a menos que existam seres humanos determinados a intervir, a alterar, a criar aquilo que é novo. [...] Exatamente em 
benefício daquilo que é novo $e$ revolucionário em cada criança é que a educação precisa ser conservadora; ela deve preservar essa novidade e introduzi-la como algo novo em um mundo velho, que, por mais revolucionário que possa ser em suas ações, é sempre, do ponto de vista da geração seguinte, obsoleto e rente à destruição (ARENDT, 2000, p. 242-243).

Podemos pensar, com Hannah Arendt, que a novidade trazida pelas gerações que adentraram as escolas públicas brasileiras, sobretudo a partir dos anos 1990, representa uma oportunidade singular de renovação da escola e da sociedade brasileira, de renovação do mundo. Quando os mecanismos de exclusão escolar passam a ser inibidos - sobretudo a partir do questionamento dos altos índices de evasão e repetência e da multiplicação de políticas que visam garantir a permanência das crianças e adolescentes na escola - a diversidade que caracteriza a sociedade brasileira pode se fazer representar em cada sala de aula, não mais como "exceção" ou "desvio", mas como uma nova realidade em grande parte das escolas públicas brasileiras. E por mais que discursos saudosistas ainda anseiem pelo "aluno ideal" - diga-se: branco, de classe média, bem comportado e bem conformado à tradicional cultura escolar, com seus modelos e ritmos de aprendizagem padronizados $-\mathrm{a}$ "nova cara" da escola pública brasileira traz a diversidade como marca irrefutável. E esse novo público escolar não é composto apenas por estudantes, mas também por docentes oriundos das camadas populares, muitos deles com um forte sentimento de identificação com seus alunos, reconhecendo-se como parte dos grupos até então alijados do espaço escolar.

A partir de depoimentos de professores que atuam em escolas públicas, podemos mapear algumas situações recorrentes e compreender dilemas e desafios vivenciados cotidianamente por professores comprometidos com o trato da diversidade e com a reeducação das relações étnicoraciais no espaço escolar ${ }^{7}$ :

[...] Quando esses excluídos começaram a apoderar do espaço da escola, porque nós chegamos à escola. Houve um momento que nós não estávamos na escola. A escola era uma escola formada por mulheres, as professoras eram todas assim, pareciam Barbie, todas bonitinhas as professoras.
[...] vamos dizer que pularam o muro $e$ adentraram na escola, isso foi um problema enorme na escola. Porque a escola, o sistema estava acostumado a lidar com aqueles que são os "individuos normais", nós entramos para criar problema [*]; porque você trouxe a discussão da favela, a discussão da exclusão, a discussão do sindicato, você trouxe isso tudo para dentro da escola, colocou no meio da sala dos professores. [...]

Essa diversidade que configura também o público docente não significa que os mecanismos de exclusão e discriminação tenham desaparecido do espaço escolar. Mas devemos reconhecer que os educadores têm sido desafiados a reconstruir propostas pedagógicas e a estabelecer novas interações com seus alunos, muitos deles assumindo que sua atividade profissional envolve compromisso ético e político. O novo contexto amplia as possibilidades de que práticas tradicionais de preconceito e discriminação racial tornem-se mais visíveis e provoquem maior estranhamento, tanto entre suas vítimas quanto entre seus praticantes, saindo do terreno da "naturalização", condição para sua superação.

Assim, sem desconhecer que o silenciamento e os tantos mecanismos de perpetuação do racismo continuam fortemente arraigados em nossas escolas - como em nossa sociedade - optamos por trazer à cena situações que evidenciam processos de mudança, fragmentos do dia-a-dia escolar que mostram professores inquietos com os desafios que lhes batem à porta, alguns deles assumindo posturas bastante pró-ativas no processo de implementação da legislação educacional de combate ao racismo e de valorização da história e cultura africana e afro-brasileira.

Um flagrante de uma dessas situações chega a nós pelo relato da professora Marilda ao descrever uma situação vivenciada em sua sala de aula:

Teve um dia que eu tava trabalhando, nem era com a discussão [...] eles estavam trabalhando com produção de texto, e um aluno fez uma brincadeira lá, chamou uma menina de macaca, [...] aí eu comecei a ver aquele zum zum zum na sala, um falou assim com o menino "olha, isso é preconceito, isso é racismo, a professora Marilda e a professora Ana já falaram, olha só, essas brincadeiras, que você ta fazendo 
com o colega aí, se ele quiser, ele pode te levar na justiça, isso é crime". E esses meninos falaram tanta coisa, tanta coisa com essa criança, ele ficou assim, o olhar dele, o semblante dele caiu, e ele olhou prá mim, ele olhou prá mim e procurou uma ajuda, um apoio, né, um socorro, porque dentro dos pares dele não tinha, cada um dos meninos falou uma coisa, então um falou assim: "você acha que você é branco? Pensa, olha, você acha que você é branco?" Ai eu falei com ele, perguntei prá ele, "olha, você antes fazia essas brincadeiras e tal, falava desse jeito porque você achava que era só uma brincadeira, né?" "É, professora, eu tô só brincando". Ai eu falei: "e agora? Tanto eu quanto Ana, seus colegas, estamos conversando, nós falamos isso o tempo todo." Porque eu comecei a trabalhar pela fala deles, da forma como eles tratam, porque é muito assim, é carregada mesmo de preconceito, as brincadeiras, a fala, os apelidos, então ele falou assim "É, eu sei que não é brincadeira". "Então, porque que você falou? Por acaso você acha que existe macaco só preto, você conhece as espécies de macaco, eu vou trazer fotos e vou te mostrar." Ai ele ficou assim, sem graça, e eu senti que os meninos ficaram assim, meio que revoltados com ele, aí eu parei a aula, eu achei que ali não era importante mais a produção de textos, que o foco da conversa tinha que ser diferente, e eu falei com eles, né, eu parabenizei os outros meninos, e eu falei com eles que aquela discussão que eles fizeram ali, eles iam levar para qualquer lugar que eles tivessem, em outros espaços da casa, onde eles transitassem, com os coleguinhas, na hora do recreio. Aí eles começaram a me contar as coisas, eles chegavam e falavam assim: "olha professora, aquele menino ali me chamou de dentuço, me chamou de macaco, me chamou disso, me chamou daquilo, isso é preconceito não é??" Então, eles tinham uma abertura muito grande de conversar isso comigo e com a outra professora, porque a gente se abriu pra essa discussão mesmo (SANTOS, 2010, p. 149).

O episódio relatado pela professora Marilda apresenta semelhanças com inúmeras outras situações que ocorrem em salas de aula e outros espaços de convivência social. Embora muitos acreditem fazer parte do passado, tais situações têm ganhado maior visibilidade na mídia e suscitado acalorados debates, sobretudo quando envolvem eventos de grande repercussão, como as partidas de futebol As reações e questionamentos que provocam são indícios da dificuldade de boa parte da população brasileira em lidar com as manifestações públicas de racismo. É possível continuar considerando "brincadeira" o caso de um jogador chamado de "macaco" dentro do estádio de futebol? E quando isso ocorre fora do alcance das câmaras de TV, em espaços de convivência e formação, como é o caso da escola? O que dizem sobre isso professores que testemunham, cotidianamente, situações como esta?

O episódio na sala da professora Marilda suscita reflexões sobre relação entre educação, ética e cuidado com o outro, entendendo que são muitos os "outros" envolvidos na situação: a criança que é discriminada, a criança que discrimina, os colegas que "tomam partido", a professora que assume posicionamentos, a identidade étnico-racial permanentemente interrogada - quem é negro, ou branco, no Brasil? O episódio parece revelar algumas das facetas que constituem o processo de reeducação das relações étnico-raciais, conforme preconiza a legislação: o trabalho sistemático que a professora conta estar realizando não impede que as manifestações de racismo continuem a acontecer, mas cria possibilidades para que sejam identificadas e interpeladas, não apenas pela docente, mas pelos próprios estudantes. A criança vítima de preconceito já não está sozinha, conta com a solidariedade e apoio de seus colegas. A criança que cometeu uma injúria racial sente-se acuada, acusada de ter cometido um "crime". Busca apoio e proteção da professora, ou talvez conclame por uma intervenção que seja mais educativa e menos punitiva. Compreendendo a educação como espaço do diálogo e do cuidado com o outro, podemos identificar, neste episódio, um significativo exemplo de como as crianças esperam que os adultos educadores se posicionem, intervenham, sejam... educadores. Esperam que a escola seja o lugar privilegiado do aprendizado pelo diálogo e pelo exemplo, e não simplesmente o lugar da punição e da criminalização, ainda que o conhecimento das leis possa ser um dos importantes instrumentos para alcançar este propósito. Podemos dizer que o debate entre aquelas crianças e sua professora evidencia que "algo se passou" com aquele grupo, e que esse 
algo não pode ser reduzido à aquisição de novas informações, inscrevendo-se no campo da "experiência". Sobre isso, vale pensar o significado da experiência e o sujeito da experiência, como nos propõe Jorge Larrosa:

A experiência, a possibilidade de que algo nos passe ou nos aconteça ou nos toque, requer um gesto de interrupção, um gesto que é quase impossível nos tempos que correm: requer parar para pensar, para olhar, parar para escutar, pensar mais devagar, olhar mais devagar e escutar mais devagar; parar para sentir, sentir mais devagar, demorar-se nos detalhes, suspender a opinião, suspender o juízo, suspender a vontade, suspender o automatismo da ação, cultivar a atenção e a delicadeza, abrir os olhos e os ouvidos, falar sobre o que nos acontece, aprender a lentidão, escutar os outros, cultivar a arte do encontro, calar muito, ter paciência e dar-se tempo e espaço. [...] o sujeito de experiência seria algo como um território de passagem, algo como uma superfície de sensibilidade na qual aquilo que passa afeta de algum modo, produz alguns afetos, inscreve algumas marcas, deixa alguns vestígios, alguns efeitos (LARROSA, 2004, p. 160).

O episódio em foco nos parece carregado de forte carga emocional, evidenciando que "aquilo que passa afeta de algum modo, produz alguns afetos, inscreve algumas marcas, deixa alguns vestígios, alguns efeitos" nos sujeitos que ali se confrontam. O que, exatamente, se passou com aquelas crianças, antes e durante o referido episódio, não podemos saber ao certo. Mas tendo em vista o relato de diversos professores que vêm encarando o desafio de tematizar a questão racial em sala de aula, podemos arriscar a hipótese de que em muitas dessas salas de aula tem acontecido algo mais do que a introdução de um novo componente curricular, com significativas experiências sendo compartilhadas pelos sujeitos que ali se encontram.

Muitas dessas experiências estão ancoradas em uma perspectiva de encontro com o outro, em uma dimensão ética que permite refletir e rever valores de uma determinada época, ou do próprio agir do indivíduo no mundo. Quando estudantes e professores são instigados a enxergar o "outro", no contexto de relações mais democráticas e igualitárias, quando esse "outro" passa a representar um contraponto, interpelando e desnaturalizando práticas de preconceito e discriminação, nos deparamos com a possibilidade de fazer da escola a morada da diversidade, em sua dimensão ética e política, o que implica também a experiência da alteridade. E essa experiência já não se limita às dimensões da identidade étnico-racial, permitindo que outras formas de preconceito e discriminação, assim como outros tipos de violência, sejam desnudadas e passem a ser questionadas no âmbito das relações sociais, como bem expressou a professora Marilda, ao relatar que seus alunos passaram a partilhar experiências de preconceitos os mais diversos.

O enfrentamento das situações de preconceito, em muitas salas de aula, tem se pautado pelo investimento na afirmação e positivação da identidade negra, com a valorização de traços fenotípicos historicamente desqualificados, como os cabelos, e por uma afirmação da negritude, historicamente negada pelo ideal de branqueamento. Muitos professores que vêm empreendendo práticas pedagógicas afinadas com a nova legislação educacional têm compreendido que a reconstrução do ideal de beleza e o investimento na elevação da autoestima de crianças e adolescentes negras e negros é um importante instrumento de reeducação das relações étnico-raciais, como mostram os depoimentos a seguir (SANTOS, 2010):

[...] Teve uma aluna que escreveu assim: "Desde o início do projeto Educação pra as relações étnico-raciais, senti uma angústia e felicidade ao mesmo tempo dentro de mim, pois me incluíram mais nos trabalhos e também aprendi a respeitar mais os negros e seus valores. [...] Fizemos muitas atividades sobre o trabalho [...] Eu também descobri que sou negra e estou muito feliz por isso. Fiz uma máscara muito bonita, só eu não, todos nós. Adorei esse projeto. Sou negra".

[...] eu acho que isso está mudando a cara da nossa juventude, das nossas crianças [...] porque os meninos estão descobrindo sua beleza, os adolescentes, eles não têm mais vergonha de usar o cabelo blackpower ou aquele cabelo todo cacheado, todo 'soltão', então as meninas também usam aquelas faixas, então isso tudo, de alguma 
maneira, eu acredito, que ta levantando a autoestima desse povo que há tantos anos vem massacrado, né [...]] quando a gente trabalha esse projeto na escola, a gente tá reafirmando o valor desse menino, dessa menina negra, dessa mulata, sabe, e eles tão reconhecendo que eles são tão capazes quanto outros, né [...]

[...] Os meninos ficavam, alguns, até exaltados, né, no calor da discussão... Mas foi muito legal, muito legal mesmo, como que eles começaram a pensar sobre isso, e se respeitar e se impor, independente de cor de pele, como que alguns alunos conseguiram ficar mais firmes em cima dessa questão [...]

Deve-se reconhecer que não apenas a aparência física é alvo de preconceitos e discriminações. $\mathrm{O}$ racismo brasileiro se configurou, historicamente, também pela negação e desvalorização de práticas culturais de origem africana ou afro-brasileiras. A compreensão desses aspectos demanda ampliar as discussões e o referencial teórico, sendo necessário investimentos que extrapolam os objetivos deste texto.

\section{Considerações Finais}

A nova morada da ética, em que o outro entra em cena, é a diversidade. Ela pode minimizar e até superar preconceitos e intolerâncias de diferentes naturezas. A construção de um éthos do diverso exige profunda reflexão, em um processo de consciência do que é o preconceito e, consequentemente, dos significados de sua ação violenta, que é o racismo. No campo da ação prática, trata-se de um exercício de atitude ética, aprendida a longo prazo, no reconhecimento do outro. Por isso, se inscreve no terreno da educação, trabalho de longo prazo sobre as novas gerações.

Podemos voltar a Hannah Arendt, para lembrar que a educação é o terreno do humano e, portanto, da ética e da política, terreno do cuidado com o outro e do cuidado com o mundo.

A educação é o ponto em que decidimos se amamos o mundo o bastante para assumirmos a responsabilidade por ele $e$, com tal gesto, salvá-lo da ruína que seria inevitável não fosse a renovação e a vinda dos novos e dos jovens. A educação é, também, onde decidimos se amamos nossas crianças o bastante para não expulsá-las de nosso mundo e abandoná-las a seus próprios recursos, e tampouco arrancar de suas mãos a oportunidade de empreender alguma coisa nova e imprevista para nós, preparando-as em vez disso com antecedência para a tarefa de renovar um mundo comum (ARENDT, 2000, p. 247).

E se assumimos que este mundo humano é o mundo da diversidade, a educação deve ser, privilegiadamente, espaço de acolhimento do diverso, numa compreensão de que a diversidade nos constitui como humanos e que a negação, silenciamento ou destituição de sua potencialidade humanizadora, nos afasta de nossa própria condição humana.

Buscar formas racionais para enfrentar o preconceito, discuti-lo incansavelmente, formando atitudes não racistas, é dever dos educadores, que têm na instituição escola um lugar privilegiado para a formação de conceitos novos, capazes de abrir possibilidades de compreensão do real. Reconhecer o outro em sua diversidade é pensá-lo no seu tempo de formação. Ao se refletir sobre este outro em sua concretude, estamos no caminho de uma nova morada do éthos no campo da diversidade. A morada da diversidade, nestes anos, avançou no campo do éthos legal. No Brasil, a promulgação das leis 10.639/03 e 11.645/08 têm sido os melhores exemplos. No entanto, em termos de formação, é necessário que o éthos se consolide em sua tríade relacional, legal, moral e ética. Para que a formação para o outro se consolide no campo ético, a escola precisa reconhecer no campo da diferença, a diversidade. Um tipo de diversidade que tem sofrido preconceitos e racismo relacionados ao fenótipo e ao modo de se perceber o outro enquanto um ser de escolhas e de direitos.

\section{Notas}

1 A esse respeito, ver Atlas Racial Brasileiro, PNUD, 2005, Disponível em http://www.pnud.org.br/.

$2 \mathrm{O}$ movimento negro configurou-se como um dos principais e mais organizados movimentos sociais, neste período. Marco importante neste processo foi a criação do Movimento Negro Unificado MNU, em 1978, com intuito de articular entidades diversas e demarcar o caráter político da luta contra a discriminação racial. Esse movimento se 
desdobrou em diferentes frentes de atuação e deu origem a algumas centenas de entidades, associações e Organizações Não-Governamentais, em todo o país

3 A temática étnico-racial aparece mais explicitamente na nova Lei de Diretrizes e Bases da Educação Nacional através de seu artigo 26, parágrafo $4^{\circ}$, que enfatiza o papel do ensino de História como espaço privilegiado para o tratamento dessas questões: "O ensino de História levará em conta as contribuições das diferentes culturas e etnias para a formação do povo brasileiro, especialmente das matrizes indígena, africana e europeia" (LDBEN 9.394/96, Art. $26 \S$ $4^{\circ}$ ).

4 Além de comparecer no volume dedicado à disciplina História, a ideia de valorização da diversidade cultural e étnico-racial ganha destaque nos chamados "temas transversais", que conta com um volume denominado "Pluralidade Cultural".

5 A esse respeito, ver texto das Diretrizes Curriculares nacionais para a Educação das Relações Étnico-Raciais e para o Ensino de História e Cultura Afro-Brasileira e Africana, MEC, 2004, p. 9.

6 Ver, entre outras, as pesquisas de CAVALLEIRO (2001), FAZZI (2004), SANTOS (2010).

$7 \mathrm{O}$ relato do professor, assim como de outros aqui transcritos, foi concedido durante um evento promovido pela Secretaria Municipal de Educação de Contagem, MG, denominado "Redes de Trocas", ocorrido em maio de 2008. Sendo realizadas em pelo menos dez sessões, as Redes de Trocas fizeram parte da preparação para um evento maior, a "Semana de Combate ao Racismo", que envolveu professores e estudantes de diferentes níveis de ensino, das escolas públicas deste município. Tal evento tornou-se objeto de estudo da pesquisa de Doutorado de Santos (2010), em que foram analisados os depoimentos de cerca de cem professores participantes das Redes de Trocas, entre outros dados. Os nomes dos professores são fictícios, conforme descrito no referido trabalho.

\section{Referências}

ARENT, Hannah. A crise da Educação. In: Arent, Hannah. Entre o passado e o futuro. Tradução:
Mauro W. Barbosa. $5^{\text {a }}$ Ed. São Paulo: Perspectiva, 2000. 348p.

BOBBIO, Norberto. Elogio da Serenidade e outros escritos morais. São Paulo: Unesp, 2002.

BRASIL. Ministério da Educação/SECAD/ Secretaria Especial de Políticas de Promoção da Igualdade Racial-SEPPIR. Diretrizes Curriculares Nacionais para a Educação das Relações ÉtnicoRaciais e para o Ensino de História e Cultura AfroBrasileira e Africana. Brasília, 2004.

BRASIL. Parâmetros Curriculares Nacionais. História e Geografia. Brasília: MEC/SEF, 1997.

BRASIL. Presidência da República. Lei $n^{\circ}$ 10.639, de 9 de janeiro de 2003. Altera a Lei ${ }^{\circ} 9.394$, de 20 de dezembro de 1996, que estabelece as diretrizes e bases da educação nacional, para incluir no currículo oficial da rede de ensino a obrigatoriedade da temática "História e Cultura Afro-Brasileira", e dá outras providências.

CANDAU, Vera Maria (Coord.). Somos todas iguais? Escola, discriminação e educação em direitos humanos. Rio de Janeiro: DP\&A, 2003.

CAVALLEIRO, Eliane dos Santos. (Org.). Racismo e Anti-Racismo na Educação - repensando nossa escola. São Paulo: Selo Negro Edições, 2001.

FAZZI, Rita de Cássia. $O$ drama racial de crianças brasileiras: socialização entre pares e preconceito. Belo Horizonte: Autêntica, 2004.

FERREIRA, Amauri C. \& GOMES, Nilma L. A morada Docente nas Trilhas da Diversidade. In: PASSOS, Mauro (Org.). A Mística da Identidade Docente - tradição, missão e profissionalização. Belo Horizonte: Fino Traço, 2011.

FERREIRA, Amauri Carlos. A Morada da ética Aplicada. Belo Horizonte/MG: Cadernos da Assembleia Legislativa de Minas Gerais. 2010. Consultado em 28/06/2015. https://www.almg.g ov.br/opencms/export/sites/default/consulte/publica coes_assembleia/periodicas/cadernos/arquivos/pdfs/ 19/3_morada_etica_aplicada.pdf

GOMES, Nilma Lino. Entrevista - Educação e Diversidade: Direito e Ação Afirmativa. In: Retratos da Escola - Dossiê Educação e 
Diversidade. V-7, n-13, Julho a dezembro de 2013. Disponível em http://www.cnte.org.br/images/stori es/retratos_da_escola/retratos_da_escola_13_2013.p df

GUIMARÃES, Antonio Sérgio Alfredo. Racismo e AntiRacismo no Brasil. São Paulo: Fundação de Apoio à Universidade de São Paulo; Ed. 34, 2a ed., 2005.

LARROSA, Jorge. Experiência e paixão. In: Linguagem e Educação depois de Babel. Belo Horizonte: Autêntica, 2004, pp. 151-165.

LEVINAS, E. Ética e Infinito. Lisboa: Edições 70, 1982.

LIMA VAZ, Henrique Cláudio de. Escritos de Filosofia IV: Introdução à ética Filosófica I. São Paulo: Loyola, 1999.
MARTINEZE. \& CORTINA, Adelia. Ética. São Paulo: Edições Loyola, 2005.

SANTOS, Lorene dos. Saberes e práticas em Redes de Trocas: a temática africana e afro-brasileira em questão. Belo Horizonte: Faculdade de Educação da UFMG (Tese de Doutorado), 2010.

SCHWARCZ, Lilia Moritz. Nem preto nem branco, muito pelo contrário: cor e raça na intimidade. In:

SCHWARCZ, Lilia Moritz (Org.). História da vida privada no Brasil: contrastes da intimidade contemporânea. São Paulo: Companhia das Letras, 1998, pp. 173-244.

Racismo à brasileira. In: Ensino de História e Cultura africana e afro-brasileira Livro-texto (vários autores). Belo Horizonte: PUC Minas Virtual, 2006, pp. 36-48.

\section{Sobre os autores}

Amauri Carlos Ferreira é graduado em Filosofia. Mestre e Doutor em Ciências da Religião. Pós Doutor em Educação. Professor de Filosofia da PUC Minas, no curso de Pedagogia e nos Programas de Pós-Graduação em Educação e em Ensino de Ciências e Matemática.

Lorene dos Santos é graduada em História. Mestre e Doutora em Educação. Professora da PUC Minas, nos cursos de História e Pedagogia e no Programa de Pós-Graduação em Educação.

Recebido em junho de 2015.

Aprovado em setembro de 2015. 